\title{
Barriers and facilitators to treatment participation by adolescents in a community mental health clinic
}

Ukamaka M. Oruche, PhD, RN, PMHCNS-BC1; Sarah M. Downs, BA²; Evan D. Holloway, $\mathrm{BS}^{2}$; Claire B. Draucker, RN, PhD, FAAN ${ }^{1}$; Matthew C. Aalsma, $\mathrm{PhD}^{2}$

${ }^{1}$ Department of Environments for Health, Indiana University School of Nursing, Indianapolis; ${ }^{2}$ Department of Pediatrics, Section of Adolescent Medicine, Indiana University School of Medicine

[Preprint; final version published as:

Oruche UM, Downs S, Holloway E, Draucker C, Aalsma M. Barriers and facilitators to treatment participation by adolescents in a community mental health clinic. J Psychiatr Ment Health Nurs. 2013 May 17. Available from: http://dx.doi.org/10.1111/jpm.12076 ]

\section{Abstract}

An estimated $40-60 \%$ of children in mental health treatment drop out before completing their treatment plans, resulting in increased risk for ongoing clinical symptoms and functional impairment, lower satisfaction with treatment, and other poor outcomes. Research has focused predominately on child, caregiver, and family factors that affect treatment participation in this population and relatively less on organizational factors. Findings are limited by focus on children between 3 and 14 years of age and included only caregivers' and/or therapists' perspectives. The purpose of this descriptive qualitative study was to identify organizational factors that influenced participation in treatment, with special attention to factors that contributed to dropout in adolescents. The sample included 12 adolescent-caregiver dyads drawn from two groups in a large public mental health provider database. Analysis of focus group interview data revealed several perceived facilitators and barriers to adolescent participation in treatment and provided several practical suggestions for improving treatment participation. Implications of the findings for psychiatric mental health nurses and other clinicians who provide services to families of adolescents with mental health concerns are discussed.

This is the author's manuscript of the article published in final edited form as:

Oruche, U. M., Downs, S., Holloway, E., Draucker, C., \& Aalsma, M. (2014). Barriers and facilitators to treatment participation by adolescents in a community mental health clinic. Journal of Psychiatric and Mental Health Nursing, 21(3), 241-248. Available from: http://dx.doi.org/10.1111/ipm.12076 


\section{Barriers and facilitators to treatment participation by adolescents in a community mental health clinic}

An estimated $40-60 \%$ of children in mental health treatment drop out before completing their treatment plans (Baruch, Vrouva, \& Fearon, 2009; Hoste, Zaitsoff, Hewell, \& Le Grange, 2007; Miller, South-Gerow, \& Allin Jr., 2008). Dropout occurs when children and their families discontinue sessions despite a clinician's recommendation for on-going treatment (Luk et al., 2001). Experts define dropout in a variety of ways (Kim, Munson, \& McKay, 2012). Baruch, Vrouva, and Fearon (2009), for example, consider dropout as leaving treatment before completing 21 sessions, whereas Miller, South-Gerow, and Allin Jr. (2008) consider dropout as attending only one session. Dropout often occurs after intake or very early in the course of the treatment process (Luk et al., 2001).

Compared to children completing treatment, children who drop out are more likely to have on-going psychiatric symptoms and functional impairment, less satisfaction with treatment, and other poor outcomes (Baruch et al., 2009; Kim et al., 2012; Luk et al., 2001; Miller et al., 2008). They are also less likely to seek help for mental health problems in the future (French, Reardon, \& Smith, 2003; Gulliver, Griffiths, \& Christensen, 2010).

Research on factors that influence whether children complete or drop out of mental health treatment has focused mainly on child, caregiver, and family factors. Child factors associated with dropout include older age, ethnic minority status, and externalizing behavior problems (Baruch et al., 2009; Frairs \& Mellor, 2007; Ganz \& Tendulkar, 2006; Miller et al., 2008, Pellerin, Weems, \& Dalton, 2010; Westin, Barksdale, \& Stephan, 2013). Parent factors associated with dropout include younger age, lower educational and occupational attainment, and high levels of stress and mental illness (Friars \& Mellor, 2007; Ganz \& Tendulkar, 2006; Kane, Zotti, \& Rosenberg 2005; Kazdin \& Wassell, 2000; Luk et al., 2001; Staudt, 2003). Dropout is more likely to occur in low-income families, single parent families, and families that have undergone stressful life events such as divorce and death (Kane et 
al., 2005; Hoste et al., 2007). Most of these studies have examined mental health treatment dropout in children between 3 and 14 years of age (Block \& Greeno, 2011; Kim et al., 2012).

Some studies have focused on organizational factors associated with child dropout from mental health treatment. Evidence suggests that children and their families are less likely to drop out of treatment when they perceive that service organizations meet their needs, ensure collaborative relationships between caregivers and counselors, place reasonable demands on them, and remove obstacles to treatment (Dakof, Tejeda, \& Liddle, 2001; Garcia \& Weisz, 2002; Greener, Joe, \& Simpson, 2007; Kim et al., 2012; McKay, Hoagwood, Murray, \& Fernandez, 2004; Staudt, 2003; Thompson et al., 2007). Barriers to completing treatment include parents' perceptions that treatment was poorly organized, costly, and ineffective because of lack of provider skills (Kane, 2005; McKay et al., 2004; Thompson et al., 2007). Most studies on organizational factors that affect treatment completion have included only caregivers and/or therapists (Dakof et al., 2001; French et al., 2003; Green, Wisdom, Wolfe, Firemark, 2012). More information on organizational factors associated with treatment dropout, especially from the perspectives of adolescents, is needed to inform system-level changes to increase rates of treatment completion (Luk et al., 2001; Kim et al., 2012).

Adolescents face unique developmental challenges, including increased need for autonomy and pressure to fit in with peers (Broome, Joe, \& Simpson, 2001; Greener et al., 2007). Compared to younger children, adolescents are more cognizant of their mental health needs, play a greater role in accessing services and attending treatment sessions, and are more likely to want control over their treatment (Block \& Greeno, 2011; French, 2003). Adolescents are more likely to drop out if they are dissatisfied with treatment (Block \& Greeno, 2011).

To inform the development of strategies to decrease dropout from mental health treatment by adolescents, more information is needed about organizational factors that influence their treatment experiences from their own perspectives and those of their families (Block \& Greeno, 2011; French, 2003; Green, Wisdom, Wolfe, \& Firemark, 2012). The 
purpose of this study was to identify the barriers and facilitators to participation in outpatient counseling in a public mental health setting as described by adolescents and their caregivers.

\section{Method}

Qualitative descriptive methods were used to conduct this study. Qualitative description is a method that provides a straightforward summary of a phenomenon presented in the everyday language of the participants (Sandelowski, 2000). In qualitative descriptive studies, data are often obtained in focus groups with those who share a common concern, and content analysis is used to summarize the informational content of the groups' responses (Sandelowski, 2000). Because we wished to identify the perceptions of the participants in regard to factors that influenced the treatment involvement of the adolescents, with special attention to factors they perceived as contributing to dropout, qualitative description was the most appropriate method for this study. Sample

The study was conducted in a large publicly funded community mental health center $(\mathrm{CMHC})$ in Indianapolis, Indiana, a Midwestern state in the United States of America. The participants were recruited from a program called the Children and Adolescent Program (CAP) that offers medication management and individual and family counseling services to children 3 to 17 years old in outpatient clinics, homes, schools, or community agencies.

The sample included 12 adolescents who were 13 to 17 years of age and their caregivers. Adolescents who were in mental health treatment or who had recently dropped out of treatment were identified from the $\mathrm{CMHC}$ client database. Dropout from treatment was defined as failure to return to the $\mathrm{CMHC}$ after one or two visits, and continuation in treatment was defined as attendance for at least six visits (Luk et al., 2001). Caregivers were parents or parent surrogates. To allow for meaningful interpretation of data and comparison with previous studies, a visit was considered an individual counseling session with a social worker. All participants were required to speak English as a primary language in order to 
participate in the focus groups. Adolescents with a co-morbid diagnosis of substance abuse and those in specialized home- or school-based programs were also excluded.

\section{Recruitment}

The Indiana University Institutional Review Board approved this study. A CMHC staff member reviewed the clinic's electronic medical records (EMR) from the prior six months to identify potential participants. The data file had the potential participants' names, birth dates, phone numbers, addresses, and number of mental health appointments kept in the last six months. Twenty eligible adolescents and their caregivers were identified. Two trained research assistants (RA) from the clinic contacted the caregivers by phone to invite them and the adolescents to participate in the study. During this contact, the RA discussed the purpose of the study and the requirements for participation. Caregivers who agreed to participate and their adolescents were scheduled for a focus group meeting.

Prior to the focus groups, written consent was obtained from the caregivers for themselves and the adolescents, and verbal assent was obtained from the adolescents. Four focus groups were conducted in conference rooms at the CMHC: A group of six adolescents who had dropped out of treatment and a group of their caregivers and, four months later, a group of six adolescents who had continued in treatment and a group of their caregivers.

The focus groups were conducted by a psychologist and nurse researcher. The groups were asked open-ended questions to facilitate group discussion and to give the participants ample opportunity to discuss their experiences from their own perspectives. The questions explored the adolescents' and caregivers' perceptions of the adolescents' treatment experiences, their suggestions for improving care, and their feelings of connection with counselors and agency staff. The interviews were audiotaped, and the group facilitators made field notes detailing the number of participants in each group, where they sat in the room, and the extent to which each was involved in the discussion. Each adolescent and one caregiver per family received $\$ 10$ and $\$ 20$ department store gift cards, respectively, to 
compensate them for their time and travel. The adults spent twice as much time as the adolescents on the study.

Data Analysis

The audiotapes of the focus groups were transcribed verbatim. Data from the dropout and continuer groups were analyzed together because there were no notable group differences in responses to interview questions. The researchers analyzed the data by identifying salient and recurrent topics across transcripts. The analysis team included a research psychologist, nurse, and two clinical social workers. Each team member had considerable experience working with youth with mental health problems.

To address the study aims, the data from the interviews were divided into three topics: facilitators, barriers, and suggestions for improvement (see Table 1). Each investigator read the transcribed data independently and listed relevant data under each of these topics. The research team then met to determine what types of facilitators, barriers, and suggestions for improvement were most salient for the participants.

\section{Results}

Although both the adolescents and their caregivers identified similar facilitators and barriers to treatment and suggestions for improvement, the two groups offered different perspectives on what influenced treatment participation and thus their views are described separately. Verbatim quotes from participants are included as examples. Pseudonyms have been used to protect the privacy of the participants and clinic staff. Table 1 displays the facilitators, barriers, and suggestions for improvement offered by adolescents and their caregivers.

[See Table 1]

\section{Facilitators}


The adolescents and caregivers identified several factors that facilitated the adolescents' participation in treatment. However, caregiver involvement in counseling and positive qualities of staff members was mentioned most frequently as facilitators.

\section{Caregiver involvement in treatment}

Several adolescents suggested that caregiver involvement in treatment improved the adolescents' treatment experience. They indicated that counselors including caregivers in sessions communicated that caregivers share responsibility for the adolescents' difficulties and need to be a part of the solution. Adolescents seemed to appreciate being able to attribute some of the "blame" for their problems to their caregivers. One adolescent suggested that joint counseling "let[s] the parents know what they're doing wrong." Another explained,

...they got the therapist here talk to you... they bring your parents in [to discuss]... what your parents are doing wrong, not only us doing wrong. See, when parents send us to therapy, they make us look like it's all the kids' fault.

Many of the caregivers also suggested that being included in the adolescents' sessions facilitated treatment. Opportunities for involvement provided caregivers with a better understanding of the problems the adolescents experienced. Some caregivers expressed relief at being able to "put a name" to the adolescents' mental health problems and to learn more about their diagnoses. In addition, being involved in the adolescents' treatment allowed caregivers the opportunity to learn how to be aware of and manage the adolescents' behaviors and concerns. Some caregivers said that participating in the counseling taught them to see things from the adolescents' perspectives, leading to improved communication and better relationships. One caregiver explained,

... We used to break in [on] each other sentences when we're talking, but now we're learning to listen [to] one another until we finish, before the other one starts. We still... got a long way to go but we can see improvement between us. ... And she's 
[the counselor's] teaching me how to give him a little more leeway and a little more trust, and so he's doing a little bit better.

Positive qualities of staff

Some adolescents and caregivers also discussed positive qualities exhibited by the CMHC staff that facilitated the adolescents' treatment. Many of the adolescents believed that being able to get along well with their counselors made them more willing to attend counseling and actively participate in their sessions. One adolescent described a counselor who was particularly engaging. The good relationship this adolescent had with his counselor enabled effective treatment. He explained,

I loved to come. Because my [counselor]... his name was Jo and he was like the coolest dude I ever met ... we would literally go in his office and we would play poker for candy in his desk and I would always whoop him and in the midst of playing those games or whatever, he would kind of ease my problems out of me. He'd let me sit up there and speak and get it out.

Several caregivers also identified positive qualities of the CMHC staff that facilitated the adolescents' treatment. The caregivers indicated that they felt supported when counselors were attuned to their needs, especially when the counselors returned phone calls in a timely manner. One stated,

I call [counselor] ....usually you do have to leave her a message, and she gets back with you, you know, especially if it's important. She's like on it. There were some issues that came up that was off our regular visit time and I would call her and she would be right on it right away.

Caregivers also mentioned counselors' skillfulness in using specific intervention techniques to address adolescents' symptoms, enhance their functioning, and improve their interactions with others. One caregiver said that a group-based intervention technique helped her child with communication skills, and another expressed appreciation for a targeted intervention 
that helped the adolescent with anger problems. These skills had provided hope for the caregivers that the treatment would be effective.

\section{Barriers}

The adolescents and caregivers identified management complications, negative interactions with staff, and staff turnover as barriers to treatment participation by the adolescents. Concerns regarding medication also served as a barrier to successful treatment.

\section{Organizational obstacles}

Some caregivers indicated that organizational obstacles impeded the adolescents' progress in treatment. These obstacles included excessive waiting to get an appointment, difficulty in getting records transferred, and delays in obtaining prescriptions. The caregivers experienced frustration that some of these obstacles hindered the adolescents from beginning treatment. One caregiver described the challenge of procuring paperwork from another $\mathrm{CMHC}$ so that her son could begin treatment:

...she asked me to get the records from [other CMHC name] that my son had been in and that is just not possible for me. I'm much too busy, I don't have time to do it. But it seemed like it would be so much easier for her to get on the phone and fax it over to each other but she just kept calling me and calling, when you going to get them? In another case, a caregiver reported that she was unable to get her adolescent's prescription refilled due to lack of follow-up at the $\mathrm{CMHC}$ and was unable to speak to staff directly about the need for a new prescription, resulting in the adolescent running out of medication. Disruptions in taking medication were clearly a barrier to effective treatment.

Negative interactions with Staff

Some adolescents and caregivers indicated that problematic dealings with counselors affected their participation in treatment. Several adolescents said that they did not get along well with their counselors, describing them as "too strict" and "mean." One 
adolescent described an argument with her counselor during which the counselor had yelled at her. The adolescents stressed that such interactions made them less likely to actively participate in treatment.

Caregivers also reported negative interactions with staff. One caregiver described an appointment in which a staff member failed to treat her son, who had Asperger's Syndrome, with respect:

But when we met Dr. Mary, she never asked, "So how's it going with Bradley?" or "How's Bradley doing?" She did not acknowledge Bradley, nor acknowledge me as in, "Hi my name is..." She was just totally impersonal and could care less. And I was like, wait a minute, aren't we here to work on an Asperger's kid that needed to be taught that? And for her to type with the computer ... and I was just like this is not working. Immediately, I called Brenda [the counselor] and said help... and so she was able to put us with another doctor and he was wonderful.

The caregivers indicated that when staff failed to acknowledge them and the adolescents and did not convey a sense of regard, the staff lost critical opportunities to forge meaningful connections and model appropriate social behaviors. Negative interactions with staff members caused caregivers to lose confidence in the treatment.

\section{Staff turnover}

Several adolescents described opening up to a counselor only to find out that he or she was leaving the agency, requiring the adolescents to start with someone new. Caregivers similarly were concerned about frequent staff turnover. One caregiver expressed concern that this problem led to her son feeling abandoned and reluctant to continue in treatment:

They get so trusted with them that it's hard for them to open up with somebody else. You start over again, all over again... I think it would be hard for me too, you know, they're going through a lot automatically and they have opened their whole heart and soul to this person. This person knows everything about them .... 
Another caregiver's statement underscored the negative impact of staff turnover on adolescents' treatment participation:

With Kim (counselor], she would see him without me so I don't even know what they talked about. But then if she would leave, it's like, okay, he's got to do this all over again. I got him to do it the second time but I don't know if I can get him to do it the third time.

Another caregiver revealed that her adolescent's counselor, who was leaving the agency, was the only staff member with the particular expertise needed to treat the adolescent. In this case, staff turnover forced the family to either find a new $\mathrm{CMHC}$ with the expertise to treat the adolescent or suspend treatment. This caregiver stated,

Mr. Carr [counselor], was leaving Dayspring [the clinic]. So we had to get another counselor, and I went way out there on Kentucky Ave. to another CMHC, which was too far. It took me an hour to get there.

It was difficult for both adolescents and their caregivers to repeatedly build rapport with new clinicians. Staff turnover, therefore, was seen as directly contributing to treatment disruptions and, in some cases, to dropout.

\section{Medication dissatisfaction}

Two adolescents reported that issues related to medication had a negative impact on their treatment experiences. They believed that the medicine did not help them and they likened it to an illicit drug. One adolescent said that a staff member was "giving me all types of medicines trying to dope me up."

Some caregivers also shared the perception that providers were trying to "dope up" the adolescents or use medication rather than other therapeutic approaches to address the adolescents' mental health needs. One caregiver stated,

He [the staff member] really wasn't listening to what he [her son] was saying. All he wanted to do was to dope him up. And I don't want him doped up. You know, 
medication is okay, and I think he does need his medication, but he doesn't need it like he was prescribing it, you know.

In sum, staff members' unilateral decision to prescribe medication was described as a negative experience and a barrier to treatment participation.

\section{Suggestions for Improvement}

The caregivers offered several suggestions for improving participation in treatment by the adolescents in the CMHC. For the most part, the suggestions were related to practical strategies that could ease the burden of mental health treatment in lives already full of multiple demands. Several participants asked for the installation of an automatic appointment reminder system because they found it difficult to keep track of appointment cards and losing them resulted in missed appointments. One caregiver stated, "We try to keep those little cards all organized with everything else. But if they can set up an automatic system to call and say, "Hey, you know what, you have an appointment tomorrow." That would help out."

Because a number of caregivers had difficulty getting their adolescents to appointments, several suggested that the agency assist with transportation. One caregiver suggested setting up carpools to get the adolescents to group sessions. She believed that organized carpools could help improve the cohesion of the group members and provide an informal support group for caregivers.

Several caregivers suggested the CHMC organize caregiver groups that would provide education and support. They believed they could "draw strength" from other caregivers going through similar experiences. One stated that "a group for adults, maybe that would help. I know a lot of adults are willing to tell each other 'okay, this is what I'm dealing with...."

One caregiver suggested that counselors from the CHMC should be placed in the schools. She argued that these counselors would be helpful because they would be familiar with the students' mental health needs and could provide education to teachers. She 
described a situation where a staff member familiar with her son's case diffused a potentially "sticky" situation in school,

I think it would be nice to have a counselor in the schools because the schools have now gotten into a point where they're so quick to call the cops on these kids... My son got into trouble a couple of years ago and by the grace of god ... the secretary knew my kid. They were going to mace him because he's trying to run out of the school, and the secretary pulled up and said, "no, no, no, I got him. I'll take care of this." ... and she called me and she said, "He's just messed up. I don't think he's going to handle the rest of the day, you need to come pick him up."

\section{Discussion}

The findings of this study contribute to the literature by identifying organizational barriers and facilitators to enduring and consistent participation in mental health treatment by adolescents. Consistent with prior studies, we found that involving caregivers in at least some counseling sessions facilitated communication between adolescents and their caregivers, enhanced the caregivers' understanding of the adolescents' illnesses, and provided information about managing the illnesses (Thompson, Bender, Lantry, \& Flynn, 2007; Ganz \& Tendulkar, 2006; Kane et al., 2005; Luk et al., 2001). This finding, however, might not be applicable to all groups of adolescents. French, Reardon, and Smith (2003), for example, found that some at-risk youths, such as those who are homeless, involved with the justice system, abuse drugs, or engage in self-harm or suicidal behaviors, do not want their parents in counseling sessions because of privacy and confidentiality concerns.

The finding that positive staff qualities, as perceived by adolescents and their caregivers, facilitate treatment participation mirrors the work of other researchers (French et al., 2003; Green et al., 2012; Kazdin, 2000; Kim et al., 2012). Consistent with our observations, investigators often report that the nature of the therapeutic relationship accounts for the largest variance in treatment engagement and differentiates children who 
drop out from those who complete treatment (Gracia \& Weisz, 2002; McKay et al., 2004; Thompson et al., 2007; Green et al., 2012). Additionally, our finding that contact with treatment providers outside of appointment times facilitates treatment engagement is consistent with prior research (French et al., 2003; Wilson \& Deane., 2001). The concerns of our participants regarding excessive wait times for appointments, paperwork burdens, difficulties obtaining prescriptions, and limited transportation options reinforce the work of other researchers who have reported that children and families are less likely to participate in treatment when they encounter such practical obstacles (French et al., 2003; McLellan \& Meyers, 2004; Scheppers, Els, Dekker,Geertzen, \& Dekker, 2006; Staudt, 2003; Westin et al., 2013).

The role of psychotropic medication in treatment involvement is unclear. Our finding that the prescription of psychotropic medication is sometimes associated with treatment dissatisfaction has been reported by other researchers (French, Reardon, and Smith, 2003). Some researchers, however, have found that adolescents are more likely to drop out of treatment if they are not taking psychotropic medication (Pelkonen, Marttunen, Laippala, \& Lönnqvis, 2000). One possible reason for this inconsistency is that the barrier described by the participants in our study was not the medication itself, but rather the poor interactions they had experienced with providers when the medication was prescribed.

Our findings extend prior research by offering robust descriptions of a number of factors that influence treatment engagement from the perspectives of adolescents and their families. In addition, the participants provided a number of practical suggestions as to how agencies might lower treatment burden and encourage completion of sessions.

Practice Implications

The findings of the study have a number of implications for psychiatric mental health nurses (PMHNs) and other clinicians who provide services to families of adolescents with mental health problems and wish to increase participation and decrease dropout. PMHNs should actively involve caregivers in the adolescents' treatment and maintain on-going and timely communication with them. PHMNs should provide caregivers with information 
regarding the adolescents' illness and possible management strategies. Since medication management seems to be a particularly salient problem, PMHNs must provide information about the names of medications, their usage, and their risks, benefits, and side effects; explore how the adolescents and the caregivers perceive the need to take the medication; and give the family an opportunity to ask questions about the medication.

Because staff turnover seems to be an integral problem leading to treatment resistance and dropout, it needs to be addressed in mental health agencies (French et al., 2003; McLellan \& Meyers, 2004). Strategies to retain staff and/or ease transitions to new counselors need to be developed. The feasibility and effectiveness of placing counselors in school settings should be explored.

\section{Study limitations}

Although the focus group format provided a forum for the adolescents and their caregivers to share their own experiences from their own perspectives, the group settings may have precluded participants from sharing stories that were more personal or perhaps more critical of the $\mathrm{CMHC}$. The small number of participants in each group provided an adequate description of common barriers and facilitators to treatment engagement, but was not large enough to identify variations in experiences related to demographic factors (e.g., gender differences of the adolescents), the child's diagnosis, or type of services received. We also believe the small number of participants in each group may have precluded the detection of nuanced differences in experiences between treatment completers and dropouts. Because the participants were interviewed on only one occasion, we were not able to ascertain if their perceptions of barriers and facilitators changed over time. Future research should therefore include a larger sample of adolescents and their families from multiple sites who are interviewed over the course of treatment and beyond to further determine the complex ways in which organizational factors influence treatment engagement.

\section{Conclusions}


Previous research has addressed child-, caregiver-, and family-related factors that may be associated with treatment dropout, but little attention has been paid to mental health organizational factors that may be associated with dropout. Mental health professionals, including PMHNs, can best enhance treatment participation and decrease dropout by building collaborative relationships with both adolescents and their caregivers and by addressing the practical barriers that render treatment burdensome. 


\section{References}

Baruch, G., Vrouva, I., \& Fearon, P. (2009). A follow-up study of characteristics of young people that dropout and continue psychotherapy: Service implications for a clinic in the community. Child and Adolescent Mental Health, 14(2), 69-75.

Block, A. M., \& Greeno, C. G. (2011). Examining outpatient dropout in adolescents: A literature review. Child Adolescent Social Work Journal, 28, 393-420. doi: 101007/s10560-011-0237-x.

Broome, K. M., Joe, G. W., \& Simpson, D. D. (2001). Engagement models for adolescents in DATOS-A. Journal of Adolescent Research, 16(6), 608-623.

Dakof, G. A., Tejeda, M., \& Liddle, H. A. (2001). Predictors of engagement in adolescent drug abuse treatment. Journal of the American Academy of Child \& Adolescent Psychiatry, 40(3), 274-281.

Frairs, P. M., \& Mellor, D. J. (2007). Drop out from behavioral management training programs for ADHD: A prospective study. Journal of Child and Family Studies, 16(3), 427-441. doi: 10.1007/s10826-006-9096-z.

Ganz, M., \& Tendulkar, S. (2006). Mental health services for children with special health needs and their families: Prevalence and correlates of unmet needs. Pediatrics, 117 (6), 2138-2148. doi: 10.1542/peds.2005-1531.

Garcia, J. A., \& Weisz, J. R. (2002). When youth mental health care stops: Therapeutic relationship problems and other reasons for ending youth outpatient treatment. Journal of Consulting and Clinical Psychology, 70(2), 439-443. doi: 10.1037/0022-006X.70.2.439.

Green, C. A., Wisdom, J. P., Wolfe, L., \& Firemark, A. (2012). Engaging youths with serious mental illness in treatment: STARS study consumer recommendations. Psychiatric Rehabilitation Journal, 35(5), 360-368. doi: 10.1037/h0094494.

Greener, J. M., Joe, G. W., Simpson, D. D., Rowan-Szal, G. A., \& Lehman, W. E. (2007). 
Influence of organizational functioning on client engagement in treatment. Journal of substance abuse treatment, 33(2), 139-147. Doi:1016/j.jsat.2006.12.025.

Gulliver, A., Griffiths, K. M., \& Christensen, H. (2010). Perceived barriers and facilitators to mental health help-seeking in young people: A systematic review. BMC psychiatry, 10(113), 1-9. doi: 10.1186/1471-244X-10-113.

Hoste, R., Zaitsoff, S., Hewell, K., \& Le Grange, D. (2007). What dropouts teach us about retention in eating disorder treatment studies. International Journal of Eating Disorders, 40(7), 668-671.

Kane, D., Zotti, M., \& Rosenberg, D. (2005). Factors associated with health care access for Mississippi children with special health care needs. Maternal and Child Health Journal, 95(2), S23-S31.

Kazdin, A. (2000). Percieved barriers to treatment participation and treatment acceptability among antisocial children and their families. Journal of Child and Family Studies, 9(2), 1573-2843.

Kazdin, A., \& Wassell, G. (2000). Predictors of barriers to treatment and therapeutic change in outpatient therapy for antisocial children and their families. Mental Health Services Research, 2(1), 27-40. doi: 10.1023/A:1009414904228.

Kim, H., Munson, M. R., \& McKay, M. M. (2012). Engagaement in mental health treatment among adolescents and young adults: A systematic review. Child Adolescent Social Work Journal, 29, 241-266. doi: 10.1007/s10560-012-0256-2.

Luk, E. S., Staiger, P. K., Mathai, J., Wong, L., Birleson, P., \& Adler, R. (2001). Children with persistent conduct problems who dropout of treatment. European Child \& Adolescent Psychiatry, 10, 28-36.

McLellan, A. T., \& Meyers, K. (2004). Contemporary addiction treatment: A review of systems problems for adults and adolescents. Biological psychiatry, 56(10), 764-770. doi.org/10.1016/j.biopsych.2004.06.018, 
McKay, M., Hoagwood, K., Murray, L., \& Fernandez, D. (2004). Integrating evidence-based engagement interventions into "real world" child mental health settings. Brief Treatment and Crisis Intervention, 4(2), 177-186.

Miller, L., South-Gerow, M., \& Allin Jr., R. (2008). Who stays in treatment? Child and family predictors of youth client retention in a public mental health. Child Youth Care Forum, 37, 153-170.

Pelkonen, M., Marttunen, M., Laippala, P., \& Lönnqvist, J. (2000). Factors associated with early dropout from adolescent psychiatric outpatient treatment. Journal of the American Academy of Child \& Adolescent Psychiatry, 39(3), 329-336.

Pellerin, K., Costa, N., Weems, C., \& Dalton, R. (2010). An examination of treatment completers and non-completers at a child and adolescent community mental health clinic. Community Mental Health Journal. 46(3), 273-281. doi: 10.1007/s10597-0099285-5.

Sandelowski M. (2000). Whatever Happended to Qualitative Description. Research in Nursing \& Health. 23, 334-340.

Scheppers, E., Els, D., Dekker, J., Geertzen, J., \& Dekker, J. (2006). Potential barriers to the use of health services among ethnic minorities: A review. Family Practice-An International Journal, 23(3), 325-348.

Staudt, M. (2003). Helping children access and use services. Journal of Child and Family Studies, 12(1), 49-60.

Thompson, S., Bender, K., Lantry, J., \& Flynn, P. (2007). Treatment engagement: Building therapeutic alliance in home-based treatment with adolescents and their families. Contemporary Familty Therapy, 29, 39-55. Broome, K. M., Joe, G. W., \& Simpson, D. D. (2001). Engagement models for adolescents in DATOS-A. Journal of Adolescent Research, 16(6), 608-623. doi: 10.1177/0743558401166005.

Westin, A. M., Barksdale, C. L., \& Stephan, S. H. (2013). The effect of waiting time on 
youth engagement to evidence based treatments. Community Mental Health Journal. doi:10.1007/s10597-012-9585-z. Retrieved from:

http://search.yahoo.com/search;_ylt=A0oG7mpaSyJRqw4A1z5XNyoA?p=Doi\%3A10. 1007\%2Fs10597-012-9585-Z\%20\&fr2=sb-top\&fr=yfp-t-636.

Wilson, C. J., \& Deane, F. P. (2001). Adolescent opinions about reducing help-seeking barriers and increasing appropriate help engagement. Journal of Educational and Psychological Consultation, 12(4), 345-364. 


\section{Table 1}

Adolescents' and caregivers' descriptions of facilitators, barriers, and suggestions for improvement of treatment participation at the $\mathrm{CMHC}$

\begin{tabular}{|c|c|c|c|}
\hline & & \\
\hline & & Adolescents & Caregiver \\
\hline \multirow[t]{2}{*}{ Facilitators } & $\begin{array}{l}\text { Caregiver } \\
\text { involvement in } \\
\text { counseling }\end{array}$ & $\begin{array}{l}\text { Allows them to share } \\
\text { the "blame" for their } \\
\text { illness with their } \\
\text { caregivers }\end{array}$ & $\begin{array}{l}\text { Provides a better understanding of } \\
\text { the adolescents' illness and } \\
\text { knowledge about how to } \\
\text { communicate with them and manage } \\
\text { their illness }\end{array}$ \\
\hline & $\begin{array}{l}\text { Positive qualities } \\
\text { of staff }\end{array}$ & $\begin{array}{l}\text { Motivates them to } \\
\text { participate more } \\
\text { actively in therapy }\end{array}$ & $\begin{array}{l}\text { Instills a sense of support and hope } \\
\text { in dealing with the adolescents' } \\
\text { illnesses }\end{array}$ \\
\hline \multirow{4}{*}{ Barriers } & $\begin{array}{l}\text { Agency } \\
\text { obstacles }\end{array}$ & & $\begin{array}{l}\text { Delays and interferes with effective } \\
\text { treatment }\end{array}$ \\
\hline & $\begin{array}{l}\text { Negative } \\
\text { interactions with } \\
\text { staff }\end{array}$ & $\begin{array}{l}\text { Decreases motivation } \\
\text { to be actively involved } \\
\text { in treatment }\end{array}$ & $\begin{array}{l}\text { Creates frustration and lack of } \\
\text { confidence in treatment }\end{array}$ \\
\hline & Staff turnover & & Delays and disrupts treatment \\
\hline & Medications & $\begin{array}{l}\text { Makes them feel } \\
\text { "doped" }\end{array}$ & Makes adolescents feel "doped" \\
\hline \multirow{4}{*}{ Suggestions } & $\begin{array}{l}\text { Appointment } \\
\text { reminders }\end{array}$ & & $\begin{array}{l}\text { Could improve attendance and ease } \\
\text { burden of keeping track of } \\
\text { appointment card }\end{array}$ \\
\hline & $\begin{array}{l}\text { Organize } \\
\text { carpools }\end{array}$ & & $\begin{array}{l}\text { Could increase attendance at group } \\
\text { sessions, increase coherence among } \\
\text { group members, provide support for } \\
\text { caregivers }\end{array}$ \\
\hline & $\begin{array}{l}\text { Support groups } \\
\text { of caregivers }\end{array}$ & & $\begin{array}{l}\text { Could provide support and education } \\
\text { for caregivers }\end{array}$ \\
\hline & $\begin{array}{l}\text { Placing } \\
\text { counselors in the } \\
\text { schools }\end{array}$ & & $\begin{array}{l}\text { Could address the needs of } \\
\text { adolescents with mental health } \\
\text { concerns in their school settings }\end{array}$ \\
\hline
\end{tabular}

